\title{
Article \\ Changes in Tear Osmolarity and Matrix Metalloproteinase-9 Relative to Ocular Discomfort after Femtosecond Laser-Assisted Cataract Surgery
}

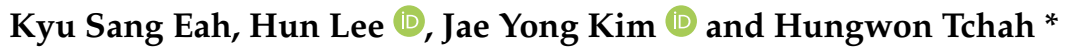

check for

updates

Citation: Eah, K.S.; Lee, H.; Kim, J.Y.; Tchah, H. Changes in Tear Osmolarity and Matrix Metalloproteinase-9 Relative to Ocular Discomfort after Femtosecond Laser-Assisted Cataract Surgery. Appl. Sci. 2021, 11, 11878. https://doi.org/10.3390/ app112411878

Academic Editors: Sang Beom Han and Alexandros A. Lavdas

Received: 14 October 2021

Accepted: 9 December 2021

Published: 14 December 2021

Publisher's Note: MDPI stays neutral with regard to jurisdictional claims in published maps and institutional affiliations.

Copyright: (c) 2021 by the authors. Licensee MDPI, Basel, Switzerland. This article is an open access article distributed under the terms and conditions of the Creative Commons Attribution (CC BY) license (https:/ / creativecommons.org/licenses/by/ $4.0 /)$.
Department of Ophthalmology, Asan Medical Center, University of Ulsan College of Medicine, Seoul 05505, Korea; kseah0124@gmail.com (K.S.E.); yhun777@gmail.com (H.L.); jykim2311@amc.seoul.kr (J.Y.K.) * Correspondence: hwtchah@amc.seoul.kr; Tel.: +82-2-3010-3680

\begin{abstract}
The aim of this study was to evaluate the changes in tear osmolarity and matrix metalloproteinase-9 (MMP-9) and their relationships with ocular discomfort in patients after femtosecond laser-assisted cataract surgery (FLACS). This retrospective observational case series reviewed medical records of 51 eyes of 51 patients who underwent FLACS. Tear osmolarity and MMP-9 were evaluated preoperatively and at 1 day, 1 week, and 1 month postoperatively. Tear osmolarity $\geq 310 \mathrm{mOsm} / \mathrm{L}$ and MMP-9 $\geq$ trace positive were defined as abnormal results. The ocular surface disease index (OSDI) was evaluated preoperatively and postoperatively at 1 month. Tear osmolarity level and the number of eyes with abnormal tear osmolarity results did not change significantly up to 1 month after surgery. MMP-9 level and the number of eyes with abnormal MMP-9 results increased at 1-day postoperatively and then decreased at 1-month postoperatively (all $p<0.001)$. Among the OSDI subscales, ocular discomfort was aggravated $(p<0.001)$ but the visual function score improved at 1 month postoperatively $(p<0.001)$. Ocular discomfort aggravated after FLACS without an increase in either tear osmolarity or MMP-9. Ocular discomfort which patients commonly experience after FLACS may be due to etiology other than development or aggravation of dry eye disease.
\end{abstract}

Keywords: femtosecond laser-assisted cataract surgery; dry eye disease; ocular surface disease; matrix metalloproteinase-9; osmolarity

\section{Introduction}

Cataract surgery is one of the most commonly performed surgical procedures worldwide, and phacoemulsification has enabled surgeons to achieve promising results with no major complications [1]. One of the recent changes in cataract surgery is the introduction of femtosecond laser-assisted cataract surgery (FLACS), allowing safer and more efficient surgery. This new technology uses a photodissection laser and has the advantages of executing precise corneal incisions, arcuate keratotomy, circular anterior capsulotomy, and lens nucleus fragmentations [2-5]. Despite these advanced technologies and excellent postoperative visual acuity results for most patients, many patients complain of dry eye symptoms, such as dryness, burning sensation, foreign body sensation, and pain [6-9].

Recent development of point-of-care diagnostics such as tear osmolarity and matrix metalloproteinase-9 (MMP-9) testing provide high sensitivity and specificity in diagnosing dry eye disease [10-13]. Recently, the American Society of Cataract and Refractive Surgery (ASCRS) Cornea Clinical Committee proposed an algorithm for preoperative diagnosis and treatment of ocular surface disease, including preoperative osmolarity and MMP-9 tests as essential screening tests [14]. However, very few studies have analyzed tear osmolarity in patients after cataract surgery and they have yet to reach a consensus [15-17]. Additionally, none have investigated MMP-9 in patients after cataract surgery. Hence, we evaluated the 
changes in tear osmolarity and MMP-9, and their relationship with ocular surface disease index (OSDI) in patients undergoing FLACS.

\section{Materials and Methods}

This retrospective observational case series was approved by the Institutional Review Board of Asan Medical Center and the University of Ulsan College of Medicine, Seoul, Republic of Korea (Approval No.: 2020-0148). This study adhered to the tenets of the Declaration of Helsinki and followed clinical practice guidelines.

A retrospective chart review was conducted on patients who underwent FLACS, performed by one surgeon (H.T.) at Asan Medical Center, between September 2019 and February 2020. Patients who met the following inclusion criteria were included: 50 years or older with age-related cataract. Patients with a history of other ocular diseases, such as glaucoma or retinal diseases, a history of prior ocular surgery, active ocular inflammation, or those taking either systemic or topical corticosteroids or topical cyclosporine were excluded from the study. The following parameters were recorded from the clinical record: demographic and clinical information including sex, age, and medical and surgical history. Ocular surface disorder assessments were performed within 1 week preoperatively (baseline) for tear osmolarity, MMP-9, and OSDI questionnaire score results. After FLACS, tear osmolarity and MMP-9 were re-assessed 1 day, 1 week, and 1 month after surgery (D1, W1, M1, respectively), and the OSDI questionnaire was re-assessed 30 days postoperatively. At the time of evaluation, tear osmolarity was assessed first, followed 10 min later by an assessment of MMP-9, and he OSDI questionnaire was completed last.

Tear osmolarity was measured using the i-Pen (i-Med Pharma, Dollard-des-Ormeaux, QC, Canada). The i-Pen determines tear osmolarity by placing the device tip on the conjunctiva of the lower lid and measuring the electrical impedance. This diagnostic tool has been shown to provide reliable and reproducible tear osmolarity results in both in vitro and in vivo conditions $[18,19]$. Previous studies have reported a recommended cutoff osmolarity range of 304 to $316 \mathrm{mOsm} / \mathrm{L}$ for the diagnosis of dry eye disease [20-26]. In this study, an osmolarity value of $\geq 310 \mathrm{mOsm} / \mathrm{L}$ in the testing eye was defined as an abnormal osmolarity as suggested by the user manual [27]. Patients were eligible to have osmolarity testing if they had not used eye drops within two hours prior to testing. Tear osmolarity was performed beforehand, as the manual recommends not to perform the test after invasive ocular diagnostic testing.

The presence of increased MMP-9 levels on the ocular surface was measured using InflammaDry (Rapid Pathogen Screening, Inc., Sarasota, FL, USA). Testing was conducted in accordance with the user manual provided. In brief, the sampling strip was dabbed in multiple locations of palpebral conjunctiva until saturated. The appearance of a red indicator line next to the blue control line indicates a positive or abnormal result which reflects a concentration of MMP-9 higher than $40 \mathrm{ng} / \mathrm{mL}$. The result is read and interpreted at least $10 \mathrm{~min}$ after completion of the sample collection. Abnormal results were also semiquantitatively interpreted using the color intensity of the result line. The results were recorded as negative (grade 0), trace-positive (grade 1), weak-positive (grade 2), positive (grade 3), and strong-positive (grade 4) using a grading index provided by the manufacturer. Grading the intensity of the InflammaDry results has been shown to correlate well with the symptoms and signs of dry eye disease patients [28].

The OSDI questionnaire is a validated questionnaire used to assess ocular surface symptoms. It has 3 subscales: ocular symptoms, vision-related function, and environmental triggers $[12,29]$. The total OSDI score is calculated by multiplying the summated answered scores by 25 and dividing by the number of questions answered. Scores of 0 to 12 are considered normal and those above 12 are considered abnormal. The subscale scores are computed similarly, with only the questions from each subscale used to generate its own score.

Subgroup analysis was performed to compare the changes in tear osmolarity, MMP-9, and OSDI results between normal and abnormal results on preoperative tear osmolarity 
tests. Additional subgroup analysis was performed in the same manner but instead according to preoperative MMP-9 test results.

\subsection{Surgical Technique}

All procedures were performed under topical anesthesia by one surgeon (H.T.). Femtosecond laser surgery was performed using the Catalys (Abbott Medical Optics Inc., Santa Ana, CA, USA) platform that includes capsulotomy and lens fragmentation. The patient was placed in a supine position on a built-in bed beneath the laser system. The suction ring and applanation cone were applied to the patient's eye. The laser platform started by performing anterior capsulotomy, followed by prefragmentation of the crystalline lens. The patient was transferred to the operating room after laser pretreatment. The main limbal incision was created using a 2.2-mm keratome, and the anterior capsule button was removed using forceps.

Removal of the nucleus and cortex was performed using the Centurion phacoemulsification system with the Ozil ${ }^{\circledR}$ torsional handpiece (Alcon Laboratories, Fort Worth, TX, USA). The preloaded monofocal intraocular lens (Tecnis ${ }^{\circledR}$ PCB00, Abbott Medical Optics, Santa Ana, CA, USA) was implanted in the capsular bag, and the ocular viscoelastic devices were removed. After hydrating the incision sites, the surgery was concluded. All patients were administered ophthalmic ketorolac $0.45 \%$ (Acuvail, Allergan, Irvine, CA, USA) 2 times per day for 2 weeks, and $0.1 \%$ fluorometholone eyedrops (Flumetholone, Santen Pharmaceutical Co., Ltd., Osaka, Japan) and levofloxacin 0.5\% ophthalmic solution (Cravit, Santen Pharmaceutical Co., Ltd., Osaka, Japan) 4 times per day for 1 month after the surgery.

\subsection{Statistical Analyses}

The Kolmogorov-Smirnov test was used to confirm data normality. A linear mixed model was used for the repeated measurements of the continuous variables and a generalized linear mixed model analysis was used to examine the differences in the repeated measurements of the noncontinuous variables. The Bonferroni correction was used when appropriate. In Bonferroni post hoc analysis, $p<0.0125$ was considered significant. For comparing two repeated measurements, such as OSDI, paired $t$-tests were used for continuous values and Wilcoxon signed rank tests for discrete variables. Subgroup analysis was performed to analyze the changes in tear osmolarity, MMP-9, and OSDI after FLACS according to the preoperative tear osmolarity and MMP-9 test results. Student's $t$-tests or Mann-Whitney U tests were used for continuous variables depending on the normality of their distribution. Chi-squared tests or Fisher's exact tests were used to compare categorical data depending on the normality of their distribution. Differences were considered statistically significant at $p<0.05$. All statistical analyses were performed using IBM SPSS Statistics for Windows, version 22.0 (IBM Corp., Armonk, NY, USA).

\section{Results}

This retrospective chart review identified 51 eyes of 51 patients who underwent FLACS. Their mean age was $67.14 \pm 8.38$ years (range 52 to 86$)$ and $35(68.6 \%)$ patients were female. The patient demographics are shown in Table 1.

Table 1. Basic demographics.

\begin{tabular}{cc}
\hline Parameter & Total (51 Eyes, 51 Patients) \\
\hline Mean age (years) $\pm \mathrm{SD}^{1}$, (range) & $67.14 \pm 8.38(52-86)$ \\
Female, $n(\%)$ & $35(68.6)$ \\
Laterality, right eye, $n(\%)$ & $19(37.3)$ \\
\hline
\end{tabular}

${ }^{1} \mathrm{SD}=$ standard deviation. 
There were no significant changes in the number of eyes with an abnormal osmolarity result $(\geq 310 \mathrm{mOsm} / \mathrm{L})$ between baseline and at D1, W1, and M1 in the study eye, with values of $27(52.9 \%), 31(60.8 \%), 20(39.2 \%)$, and $23(45.1 \%)$, respectively. Mean tear osmolarity also showed no significant postoperative changes in post hoc analysis between baseline and at D1, W1, and M1, with average values of $310.92 \pm 16.52,309.75 \pm 15.93$, $303.78 \pm 15.99$, and $304.69 \pm 14.97 \mathrm{mOsm} / \mathrm{L}$, respectively. Significant changes in MMP-9 after FLACS were seen in both the number of eyes with abnormal results and their average grade. At D1, both the number of eyes with abnormal results and the mean MMP-9 grade increased significantly compared to the baseline, with values of 46 eyes $(90.2 \%)$ and $1.94 \pm 0.97$ at baseline and 51 eyes $(100 \%, p=0.010)$ and $3.55 \pm 0.73(p<0.001)$ at D1, respectively. The number of eyes with abnormal results and the mean MMP-9 value returned to the baseline level at $\mathrm{W} 1$, with values of 46 eyes $(90.2 \%)$ and $1.73 \pm 1.13$, respectively, with no significant differences compared to the baseline. M1 showed a significant decrease in both the number of eyes with abnormal results and the average MMP-9 compared to the baseline, with values of 29 eyes $(56.9 \%, p<0.001)$ and $0.82 \pm 0.82$ $(p<0.001)$, respectively (Table 2 and Figure 1$)$.

Table 2. Changes in tear osmolarity and MMP-9 after FLACS.

\begin{tabular}{|c|c|c|c|c|c|c|c|c|}
\hline \multirow{2}{*}{ Parameter } & \multirow{2}{*}{ Baseline } & \multirow{2}{*}{1 Day } & \multirow{2}{*}{1 Week } & \multirow{2}{*}{1 Month } & \multicolumn{4}{|c|}{$p^{1}$} \\
\hline & & & & & Overall & 1 Day & 1 Week & 1 Month \\
\hline $\begin{array}{c}\text { Osmolarity, } \\
\text { abnormal, } n(\%)\end{array}$ & $27(52.9)$ & $31(60.8)$ & $20(39.2)$ & $23(45.1)$ & 0.103 & 0.427 & 0.108 & 0.323 \\
\hline Osmolarity, mean (SD) & $310.92(16.52)$ & 309.75 (15.93) & 303.78 (15.99) & 304.69 (14.97) & 0.002 & 0.711 & 0.048 & 0.146 \\
\hline $\begin{array}{c}\text { MMP-9, } \\
\text { abnormal, } n(\%)\end{array}$ & $46(90.2)$ & $51(100.0)$ & $46(90.2)$ & $29(56.9)$ & $<0.001$ & 0.010 & $>0.999$ & $<0.001$ \\
\hline $\begin{array}{c}\text { MMP-9, } \\
\text { mean (SD) }\end{array}$ & $1.94(0.97)$ & $3.55(0.73)$ & $1.73(1.13)$ & $0.82(0.82)$ & $<0.001$ & $<0.001$ & 0.061 & $<0.001$ \\
\hline
\end{tabular}

${ }^{1}$ Linear mixed model with Bonferroni post hoc analysis for continuous variables. 1 day, 1 week, and 1 month are comparisons with baseline. Generalized linear mixed model with Bonferroni post hoc analysis for noncontinuous variables. MMP-9 = matrix metalloproteinase-9; FLACS $=$ femtosecond laser-assisted cataract surgery; $\mathrm{SD}=$ standard deviation .

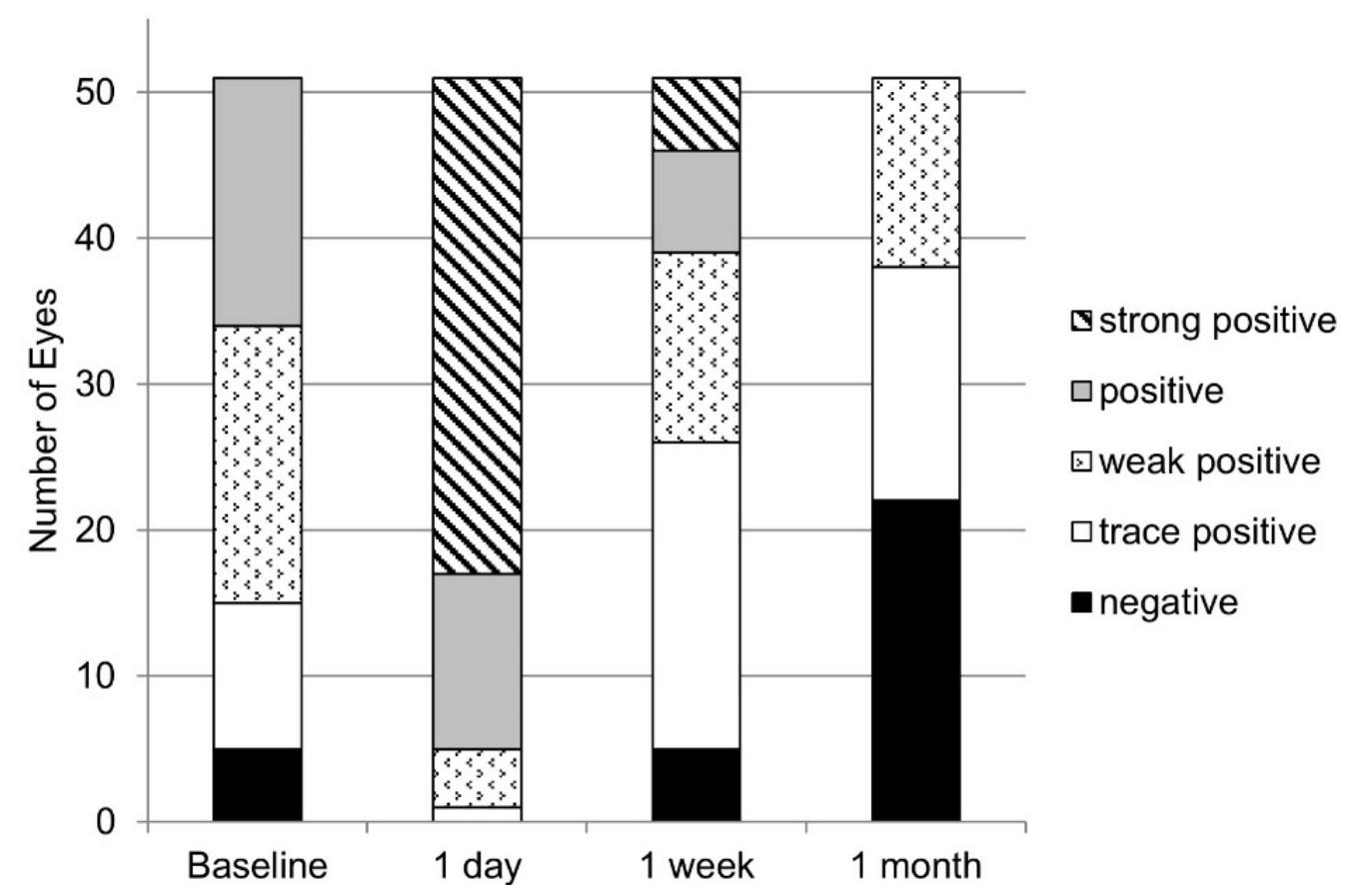

Figure 1. Change in matrix metalloproteinase-9 grade after femtosecond laser-assisted cataract surgery. 
No significant changes were seen in the number of abnormal overall OSDI results or the mean overall OSDI score 1-month postoperatively compared with preoperatively. However, the ocular discomfort subscale score significantly increased at M1 $(p<0.001)$ while the visual function subscale improved with significance at M1 $(p<0.001)$. There was no significant change in the environmental triggers subscale score (Table 3).

Table 3. Change in OSDI after FLACS.

\begin{tabular}{cccc}
\hline Parameter & Baseline & 1 Month & $p$ \\
\hline OSDI overall, abnormal, $n(\%)$ & $39(76.5)$ & $35(68.6)$ & $0.206^{1}$ \\
OSDI overall, mean (SD) & $29.45(20.36)$ & $27.94(2.79)$ & $0.651^{1}$ \\
Ocular discomfort, mean (SD) & $19.51(14.64)$ & $32.52(21.60)$ & $<0.001^{2}$ \\
Visual function, mean (SD) & $47.35(30.94)$ & $14.19(16.01)$ & $<0.001^{2}$ \\
Environmental triggers, mean (SD) & $30.56(29.80)$ & $30.06(29.35)$ & $0.770^{2}$ \\
\hline
\end{tabular}

${ }^{1}$ Wilcoxon signed rank test, ${ }^{2}$ Paired $t$-test. OSDI $=$ ocular surface disease index; FLACS $=$ femtosecond laserassisted cataract surgery; $\mathrm{SD}=$ standard deviation.

In the subgroup analysis, no significant differences were found in tear osmolarity, MMP-9, or the OSDI values between the preoperative normal and abnormal values of both tear osmolarity (Table 4) and MMP-9 (Table 5).

Table 4. Subgroup analysis according to the preoperative osmolarity result.

\begin{tabular}{|c|c|c|c|}
\hline Parameter & $\begin{array}{c}\text { Osmolarity (+) } \\
\quad(n=27)\end{array}$ & $\begin{array}{c}\text { Osmolarity }(-) \\
(n=24)\end{array}$ & $p$ \\
\hline \multicolumn{4}{|l|}{ Osmolarity } \\
\hline \multicolumn{4}{|c|}{ Abnormal, $n(\%)$} \\
\hline 1 day & $18(66.7)$ & $13(54.2)$ & $0.361^{3}$ \\
\hline 1 week & $10(37.0)$ & $10(41.7)$ & $0.735^{3}$ \\
\hline 1 month & $15(55.6)$ & $8(33.3)$ & $0.111^{3}$ \\
\hline \multicolumn{4}{|c|}{ Average, mean (SD) } \\
\hline Baseline & 323.22 (12.32) & $297.08(6.67)$ & $<0.001^{2}$ \\
\hline 1 day & $310.70(16.42)$ & 308.67 (15.65) & $0.653^{1}$ \\
\hline 1 week & 304.67 (16.02) & $302.79(16.24)$ & $0.734^{2}$ \\
\hline 1 month & $307.93(15.56)$ & 301.04 (13.69) & $0.102^{1}$ \\
\hline \multicolumn{4}{|l|}{ MMP-9 } \\
\hline \multicolumn{4}{|c|}{ Abnormal, $n(\%)$} \\
\hline Baseline & $24(88.9)$ & $22(91.7)$ & $0.192^{4}$ \\
\hline 1 day & $27(100)$ & $24(100)$ & \\
\hline 1 week & $24(88.9)$ & $22(91.7)$ & $0.739^{4}$ \\
\hline 1 month & $15(55.6)$ & $14(58.3)$ & $0.842^{3}$ \\
\hline \multicolumn{4}{|c|}{ Average, mean (SD) } \\
\hline Baseline & $1.78(1.05)$ & $2.12(0.85)$ & $0.151^{2}$ \\
\hline 1 day & $3.70(0.54)$ & $3.38(0.88)$ & $0.169^{2}$ \\
\hline 1 week & $1.52(1.01)$ & $1.96(1.23)$ & $0.192^{2}$ \\
\hline 1 month & $0.78(0.80)$ & $0.87(0.85)$ & $0.694^{2}$ \\
\hline \multicolumn{4}{|l|}{ OSDI } \\
\hline \multicolumn{4}{|c|}{ Abnormal, $n(\%)$} \\
\hline Baseline & $21(77.8)$ & $18(75.0)$ & $0.815^{3}$ \\
\hline 1 month & $20(74.1)$ & $15(62.5)$ & $0.374^{3}$ \\
\hline \multicolumn{4}{|c|}{ Average, mean (SD) } \\
\hline Baseline & $27.66(18.27)$ & $31.04(22.75)$ & $0.706^{2}$ \\
\hline 1 month & $29.91(21.37)$ & $25.72(18.39)$ & $0.590^{2}$ \\
\hline \multicolumn{4}{|c|}{ Ocular discomfort, mean (SD) } \\
\hline Baseline & $19.63(15.38)$ & $19.38(14.09)$ & $0.954^{2}$ \\
\hline 1 month & $35.65(24.79)$ & $29.00(17.18)$ & $0.369^{2}$ \\
\hline
\end{tabular}


Table 4. Cont.

\begin{tabular}{|c|c|c|c|}
\hline Parameter & $\begin{array}{l}\text { Osmolarity }(+) \\
\quad(n=27)\end{array}$ & $\begin{array}{l}\text { Osmolarity }(-) \\
\quad(n=24)\end{array}$ & $p$ \\
\hline \multicolumn{4}{|c|}{ Visual function, mean (SD) } \\
\hline Baseline & $43.75(28.91)$ & $49.64(33.90)$ & $0.553^{2}$ \\
\hline 1 month & $15.92(16.83)$ & $11.81(15.09)$ & $0.166^{2}$ \\
\hline \multicolumn{4}{|c|}{ Environmental triggers, mean (SD) } \\
\hline Baseline & $26.44(29.03)$ & $31.16(31.10)$ & $0.603^{2}$ \\
\hline 1 month & $31.09(27.64)$ & $27.69(31.62)$ & $0.410^{2}$ \\
\hline
\end{tabular}

Table 5. Subgroup analysis according to the preoperative MMP-9 result.

\begin{tabular}{|c|c|c|c|}
\hline Parameter & $\begin{array}{c}\text { MMP-9 (+) } \\
(n=46)\end{array}$ & $\begin{array}{c}\text { MMP-9 }(-) \\
(n=5)\end{array}$ & $p$ \\
\hline \multicolumn{4}{|l|}{ MMP-9 } \\
\hline \multicolumn{4}{|c|}{ Abnormal, $n(\%)$} \\
\hline 1 day & $46(100.0)$ & $5(100.0)$ & \\
\hline 1 week & $42(91.3)$ & $4(80.0)$ & $0.416^{3}$ \\
\hline 1 month & $27(58.7)$ & $2(40.0)$ & $0.641^{3}$ \\
\hline \multicolumn{4}{|c|}{ Average, mean (SD) } \\
\hline Baseline & $2.15(0.76)$ & $0.00(0.00)$ & $<0.001^{2}$ \\
\hline 1 day & $3.63(0.61)$ & $2.80(1.30)$ & $0.164^{2}$ \\
\hline 1 week & $1.80(1.15)$ & $1.00(0.71)$ & $0.154^{2}$ \\
\hline 1 month & $0.85(0.82)$ & $0.60(0.89)$ & $0.548^{2}$ \\
\hline \multicolumn{4}{|l|}{ Osmolarity } \\
\hline \multicolumn{4}{|c|}{ Abnormal, $n(\%)$} \\
\hline Baseline & $24(52.2)$ & $3(60.0)$ & $>0.999^{3}$ \\
\hline 1 day & $29(63.0)$ & $2(40.0)$ & $>0.369^{3}$ \\
\hline 1 week & $18(39.1)$ & $2(40.0)$ & $>0.999^{3}$ \\
\hline 1 month & $21(45.7)$ & $42(40.0)$ & $>0.999^{3}$ \\
\hline \multicolumn{4}{|c|}{ Average, mean (SD) } \\
\hline Baseline & 310.35 (16.53) & $316.20(17.30)$ & $0.458^{1}$ \\
\hline 1 day & $310.11(15.54)$ & $306.40(20.98)$ & $0.626^{1}$ \\
\hline 1 week & $303.48(15.95)$ & $306.60(17.90)$ & $0.724^{2}$ \\
\hline 1 month & $305.30(13.42)$ & $299.00(27.07)$ & $0.633^{1}$ \\
\hline \multicolumn{4}{|l|}{ OSDI } \\
\hline \multicolumn{4}{|c|}{ Abnormal, $n(\%)$} \\
\hline Baseline & $34(73.9)$ & $5(100.0)$ & $0.323^{3}$ \\
\hline 1 month & $30(65.2)$ & $5(100.0)$ & $0.167^{3}$ \\
\hline \multicolumn{4}{|c|}{ Average, mean (SD) } \\
\hline Baseline & $27.96(20.66)$ & $41.11(13.58)$ & $0.091^{2}$ \\
\hline 1 month & $27.04(20.25)$ & $36.20(16.23)$ & $0.218^{2}$ \\
\hline \multicolumn{4}{|c|}{ Ocular discomfort, mean (SD) } \\
\hline Baseline & $18.70(14.81)$ & $27.00(11.51)$ & $0.164^{2}$ \\
\hline 1 month & $32.16(22.56)$ & $35.83(9.59)$ & $0.395^{2}$ \\
\hline \multicolumn{4}{|c|}{ Visual function, mean (SD) } \\
\hline Baseline & $44.74(32.24)$ & $62.08(12.27)$ & $0.096^{2}$ \\
\hline 1 month & $13.78(16.73)$ & $15.00(17.13)$ & $0.264^{2}$ \\
\hline \multicolumn{4}{|c|}{ Environmental triggers, mean (SD) } \\
\hline Baseline & $27.56(30.48)$ & $38.33(23.27)$ & $0.278^{2}$ \\
\hline 1 month & $27.36(28.01)$ & $48.33(37.91)$ & $0.159^{2}$ \\
\hline
\end{tabular}

${ }^{1}$ Independent $t$-test, ${ }^{2}$ Mann-Whitney test, ${ }^{3}$ Fisher's exact test. $(+)=$ abnormal result; $(-)=$ normal result; MMP-9 = matrix metalloproteinase-9; SD = standard deviation; OSDI = ocular surface disease index. 


\section{Discussion}

In the present study, we evaluated the change in tear osmolarity and the MMP-9 level after FLACS. We found that tear osmolarity did not change up to 1 month after surgery. MMP-9 increased with significance at D1, returned to its preoperative level at W1, and then decreased significantly by M1. There was no significant change in the overall OSDI score after FLACS. However, the ocular discomfort subscale score was aggravated significantly at M1. These results suggest that the aggravated or persistent symptoms of ocular discomfort that are commonly reported by patients after FLACS may be due to factors other than an increase in tear film osmolarity or inflammatory conditions.

Dry eye disease is a multifactorial disease of the ocular surface that is accompanied by increased tear osmolarity and inflammation of the ocular surface [30]. In addition to slit-lamp evaluation, tools to diagnose dry eye disease include corneal fluorescein staining, tear film break-up time, the Schirmer test, and validated questionnaires, such as the ocular surface disease index (OSDI). However, the poor association between the signs and symptoms of dry eye disease is well known [31,32]. The recent development of point-ofcare diagnostics in diagnosing dry eye disease, such as tear osmolarity and MMP-9 testing have shown high sensitivity and specificity [10-13]. Previous studies recommend using these point-of-care diagnostic tools in evaluating ocular surface disease before performing cataract surgery $[14,33]$. Despite the development of these new diagnostic tools, only a few studies have evaluated the changes in tear osmolarity after cataract surgery $[16,17]$. No study has investigated the changes in MMP-9 after conventional cataract surgery. To the best of our knowledge, this is the first study to evaluate the changes in tear osmolarity and MMP-9 after FLACS.

It is widely accepted that patients experience ocular discomfort or symptoms of dry eye syndrome after cataract surgery [7,34-36]. In line with previous studies, we also found that patients experience aggravated ocular discomfort 1 month after FLACS. Ocular discomfort after cataract surgery has been attributed primarily to the development or aggravation of dry eye syndrome [9,37-40]. However, previous studies have shown that not all signs of dry eye syndrome are aggravated after cataract surgery. Ju et al. investigated the changes in the ocular surface and dry eye symptoms after FLACS and found that most signs of dry eye returned to their baseline level within 3 months postoperatively, although symptoms of dry eye disease remained aggravated [41]. Additionally, González-Mesa et al. [16] reported that tear osmolarity did not increase after conventional cataract surgery and they suggested that ocular surface discomfort after cataract surgery is not attributable to an increase in tear osmolarity. Despite the aggravation of ocular discomfort after FLACS, our study also found that there was no change in tear osmolarity after FLACS. Moreover, MMP-9, an important indicator of ocular surface inflammation, decreased 1 month after the surgery while the ocular surface discomfort scale score increased. If ocular discomfort after cataract surgery is due to the development or aggravation of dry eye disease, tear osmolarity or MMP-9 would be expected to be increased after surgery. However, our results suggest that the ocular discomfort patients experience after FLACS may be due to an etiology other than the development or aggravation of dry eye disease because there was no change in tear osmolarity, and there was a decrease in MMP-9 level.

The ocular discomfort that patients experience after FLACS may include symptoms such as pain, which is shared with symptoms of dry eye disease. Damage to the trigeminal nerves by inflammation after surgery and the corneal incisions could be the cause of the pain [42]. Previous studies have also proposed that persistent postsurgical pain (PPP) may present as dry eye symptoms after cataract surgery [43,44]. They found that PPP could manifest in $32-34 \%$ of patients up to 6 months postoperatively. Additionally, the administration of multiple eyedrops which contain preservatives may cause toxic effects and pain $[9,34,40]$. There also may be other etiologies to explain the postsurgical ocular discomfort after FLACS, which require further investigation. Because ocular discomfort after FLACS may be explained by an etiology other than dry eye disease, it will be im- 
portant to assess tear osmolarity and MMP-9 to evaluate and manage postsurgical ocular discomfort appropriately.

Our study found that abnormal MMP-9 levels and the number of eyes with abnormal results decreased significantly compared to the baseline level 1 month after surgery. This is thought to be due to the use of topical corticosteroids after the surgery. Topical corticosteroids cause a significant decrease in the MMP-9 level in patients with dry eye [45]. This may be explained by the suppression of cytokine expression, mitogen-activated protein kinase (MAPK) signaling pathways, c-Jun N-terminal kinase (JNK), and extracellular signal regulated kinase (ERK) in the corneal and limbal epithelial cells $[46,47]$. Therefore, we may interpret a decreased MMP-9 level after cataract surgery as reflecting decreased inflammation of the ocular surface. However, cytokines and enzymes, such as interleukin- $1 \beta$, interleukin-6, caspase 3, transglutaminase 2 , interferon- $\gamma$, and tumor necrosis factor- $\alpha$, are also known to be released during dry eye disease [48]. There is a chance that our study may not have detected ocular surface inflammation since only MMP-9 has been measured in this study [49].

We also observed an increase in MMP-9 1 day after FLACS. This was probably caused by several factors, such as damage to the cornea, inflammation, or mechanical trauma due to the use of a suction ring. Yu et al. [50] explained that the higher risk of dry eye symptoms after FLACS compared to conventional cataract surgery may be due to the difference in the use of a suction ring during the femtosecond laser procedure. Previous studies have shown that the use of a suction ring during laser in situ keratomileusis causes damage to the conjunctival epithelium and a loss of goblet cells [51-54]. Inflammatory conditions and a decrease in mucin secretion may have stimulated the production of MMP-9 after FLACS. However, whether this is only observed after FLACS or also after conventional cataract surgery needs further investigation.

There were no significant changes in tear osmolarity after FLACS. Several studies have shown conflicting results regarding changes in tear osmolarity after conventional cataract surgery. The study of Igarashi et al. [55] resulted in a significant increase in tear osmolarity up to 4 weeks after surgery. Khanal et al. [15] showed an increase in tear osmolarity in the early postoperative period that normalized to baseline level compared to the preoperative tear osmolarity. Dissimilarly, González-Mesa et al. [16] showed no significant changes in tear osmolarity before and after cataract surgery. Our results also did not show increased tear osmolarity after FLACS. These studies have used topical corticosteroids after cataract surgery for 4 weeks. Normalization of tear osmolarity may be due to the use of topical corticosteroids. Lee et al. [56] treated patients with moderate to severe dry eye disease with topical 1\% methylprednisolone for 8 weeks and found a significant decrease in tear osmolarity compared to baseline level. Further investigation regarding the effects of corticosteroid on tear osmolarity after cataract surgery is needed.

It is noteworthy to mention that there was no difference in postoperative tear osmolarity, MMP-9 level, or OSDI scores between those with normal and abnormal results of preoperative tear osmolarity and MMP-9 tests. González-Mesa et al. [16] compared patients with normo-osmolarity and hyperosmolarity on their preoperative evaluation and found that OSDI scores were significantly higher in the hyperosmolarity group 3 months after the surgery while there was no difference at 1 month after the surgery. They suggested that the presence of hyperosmolar tears before cataract surgery may be a risk factor for aggravating dry eye disease symptoms after surgery. Our subgroup analysis according to the preoperative tear osmolarity and MMP-9 results showed that there were no differences in tear osmolarity, MMP-9, or OSDI scores between the normal and abnormal groups. This suggests that preoperative osmolarity and MMP-9 results may not be predictive of the ocular surface conditions 1 month after the surgery. Moreover, patients with abnormal tear osmolarity and MMP-9 before surgery did not show an increased OSDI score or ocular discomfort subscale compared to normal preoperative patients with normal tear osmolarity and MMP-9. This may be due to the cutoff value of tear osmolarity to diagnose dry eye disease. There are several recommended cutoff values ranging from $304 \mathrm{mOsm} / \mathrm{L}$ 
to $316 \mathrm{mOsm} / \mathrm{L}$. [20-26]. The lack of consensus of tear osmolarity in diagnosing ocular surface disorder may have resulted in uncorrelation between tear osmolarity and OSDI score. However, ocular surface dysfunction can be asymptomatic and OSDI score alone may not reflect the existence of ocular surface disease. This is consistent with previous studies that patients with ocular surface dysfunction may not present symptoms of ocular discomfort $[33,57]$. Ocular surface disease may cause abnormal tear film that could affect preoperative keratometric and topographic measurement, which could cause intraocular lens calculation errors and unsatisfactory visual results [58-60]. Therefore, even though preoperative tear osmolarity and MMP-9 measurements may not predict ocular surface conditions after FLACS, their role of screening ocular surface disease before surgery is valuable for satisfactory outcomes.

Limitations of our study are its retrospective design and small sample size. This study did not have a control group that had not undergone FLACS. Additionally, the follow-up period was rather short to adequately analyze the long-term changes in tear osmolarity and MMP-9 after FLACS. Traditional examinations to evaluate dry eye disease, such as corneal fluorescein staining, tear film break-up time, and the Schirmer test, have not been conducted in this study. All surgeries were performed by a single surgeon, which may limit generalizability of the results. However, we believe that measuring tear osmolarity and MMP-9 using point-of-care diagnostics are objective tests and are sufficient to evaluate dry eye disease due to their high sensitivity and specificity. Despite these limitations, this is the first study to investigate the change in the MMP-9 level after cataract surgery and it provides valuable information about the ocular discomfort commonly seen after cataract surgery.

\section{Conclusions}

In conclusion, we observed that tear osmolarity remained unchanged and that the MMP-9 level decreased 1 month after FLACS, although ocular surface discomfort increased. This suggests that the ocular discomfort patients commonly experience after FLACS may be due to an etiology other than the development or aggravation of dry eye disease. Clinicians should monitor these parameters to effectively evaluate and relieve the ocular discomfort patients experience after cataract surgery.

Author Contributions: Conceptualization, K.S.E., H.L., J.Y.K. and H.T.; methodology, K.S.E. and H.T.; software, K.S.E.; validation, K.S.E., H.L., J.Y.K. and H.T.; formal analysis, K.S.E.; investigation, K.S.E.; resources, K.S.E., H.L., J.Y.K. and H.T.; data curation, K.S.E.; writing-original draft preparation, K.S.E.; writing-review and editing, H.T.; visualization, K.S.E., H.L., J.Y.K. and H.T.; supervision, H.T.; project administration, K.S.E., H.L., J.Y.K. and H.T. All authors have read and agreed to the published version of the manuscript.

Funding: This research received no external funding.

Institutional Review Board Statement: The study was conducted according to the guidelines of the Declaration of Helsinki, and approved by the Institutional Review Board of Asan Medical Center and the University of Ulsan College of Medicine, Seoul, Republic of Korea (Approval No.: 2020-0148).

Informed Consent Statement: Patient consent was waived due to the retrospective nature.

Data Availability Statement: Data are available upon request from the authors.

Conflicts of Interest: Authors declare no conflict of interest.

\section{References}

1. Foster, A. Vision 2020: The cataract challenge. Community Eye Health 2000, 13, 17-19.

2. Ale, J.B. Intraocular lens tilt and decentration: A concern for contemporary IOL designs. Nepal J. Ophthalmol. $2011,3,68-77$. [CrossRef]

3. Nagy, Z.Z.; Kranitz, K.; Takacs, A.I.; Mihaltz, K.; Kovacs, I.; Knorz, M.C. Comparison of intraocular lens decentration parameters after femtosecond and manual capsulotomies. J. Refract. Surg. 2011, 27, 564-569. [CrossRef] [PubMed]

4. Oshika, T.; Kawana, K.; Hiraoka, T.; Kaji, Y.; Kiuchi, T. Ocular higher-order wavefront aberration caused by major tilting of intraocular lens. Am. J. Ophthalmol. 2005, 140, 744-746. [CrossRef] [PubMed] 
5. Sanders, D.R.; Sarver, E.J.; Cooke, D.L. Accuracy and precision of a new system for measuring toric intraocular lens axis rotation. J. Cataract Refract. Surg. 2013, 39, 1190-1195. [CrossRef]

6. Han, K.E.; Yoon, S.C.; Ahn, J.M.; Nam, S.M.; Stulting, R.D.; Kim, E.K.; Seo, K.Y. Evaluation of dry eye and meibomian gland dysfunction after cataract surgery. Am. J. Ophthalmol. 2014, 157, 1144-1150.e1141. [CrossRef]

7. Sutu, C.; Fukuoka, H.; Afshari, N.A. Mechanisms and management of dry eye in cataract surgery patients. Curr. Opin. Ophthalmol. 2016, 27, 24-30. [CrossRef]

8. Szakáts, I.; Sebestyén, M.; Tóth, É.; Purebl, G. Dry Eye Symptoms, Patient-Reported Visual Functioning, and Health Anxiety Influencing Patient Satisfaction After Cataract Surgery. Curr. Eye Res. 2017, 42, 832-836. [CrossRef] [PubMed]

9. Li, X.M.; Hu, L.; Hu, J.; Wang, W. Investigation of dry eye disease and analysis of the pathogenic factors in patients after cataract surgery. Cornea 2007, 26, S16-S20. [CrossRef]

10. Sambursky, R.; Davitt, W.F., 3rd; Friedberg, M.; Tauber, S. Prospective, multicenter, clinical evaluation of point-of-care matrix metalloproteinase-9 test for confirming dry eye disease. Cornea 2014, 33, 812-818. [CrossRef]

11. Sambursky, R.; Davitt, W.F., 3rd; Latkany, R.; Tauber, S.; Starr, C.; Friedberg, M.; Dirks, M.S.; McDonald, M. Sensitivity and specificity of a point-of-care matrix metalloproteinase 9 immunoassay for diagnosing inflammation related to dry eye. JAMA Ophthalmol. 2013, 131, 24-28. [CrossRef]

12. Schiffman, R.M.; Christianson, M.D.; Jacobsen, G.; Hirsch, J.D.; Reis, B.L. Reliability and Validity of the Ocular Surface Disease Index. Arch. Ophthalmol. 2000, 118, 615-621. [CrossRef] [PubMed]

13. Sullivan, B.D.; Whitmer, D.; Nichols, K.K.; Tomlinson, A.; Foulks, G.N.; Geerling, G.; Pepose, J.S.; Kosheleff, V.; Porreco, A.; Lemp, M.A. An objective approach to dry eye disease severity. Investig. Ophthalmol. Vis. Sci. 2010, 51, 6125-6130. [CrossRef]

14. Starr, C.E.; Gupta, P.K.; Farid, M.; Beckman, K.A.; Chan, C.C.; Yeu, E.; Gomes, J.A.P.; Ayers, B.D.; Berdahl, J.P.; Holland, E.J.; et al. An algorithm for the preoperative diagnosis and treatment of ocular surface disorders. J. Cataract Refract. Surg. 2019, 45, 669-684. [CrossRef]

15. Khanal, S.; Tomlinson, A.; Esakowitz, L.; Bhatt, P.; Jones, D.; Nabili, S.; Mukerji, S. Changes in corneal sensitivity and tear physiology after phacoemulsification. Ophthalmic Physiol. Opt. J. Br. Coll. Ophthalmic Opt. 2008, 28, 127-134. [CrossRef] [PubMed]

16. González-Mesa, A.; Moreno-Arrones, J.P.; Ferrari, D.; Teus, M.A. Role of Tear Osmolarity in Dry Eye Symptoms after Cataract Surgery. Am. J. Ophthalmol. 2016, 170, 128-132. [CrossRef] [PubMed]

17. Elksnis, E. E.; Lāce, I.; Laganovska, G.; Erts, R. Tear osmolarity after cataract surgery. J. Curr. Ophthalmol. 2019, 31, 31-35. [CrossRef]

18. Chan, C.C.; Borovik, A.; Hofmann, I.; Gulliver, E.; Rocha, G. Validity and Reliability of a Novel Handheld Osmolarity System for Measurement of a National Institute of Standards Traceable Solution. Cornea 2018, 37, 1169-1174. [CrossRef] [PubMed]

19. Reis, H.; Grenier, S.; Albuquerque, D. A Comparison of In Vivo and In Vitro Osmometers for the Assessment of Dry Eye Disease. Clin. Refract. Optom. 2017, 26, 47-49.

20. Gilbard, J.P.; Farris, R.L.; Santamaria, J., 2nd. Osmolarity of tear microvolumes in keratoconjunctivitis sicca. Arch. Ophthalmol. 1978, 96, 677-681. [CrossRef]

21. Khanal, S.; Tomlinson, A.; McFadyen, A.; Diaper, C.; Ramaesh, K. Dry eye diagnosis. Investig. Ophthalmol. Vis. Sci. 2008, 49, 1407-1414. [CrossRef]

22. Lemp, M.A.; Bron, A.J.; Baudouin, C.; Benítez Del Castillo, J.M.; Geffen, D.; Tauber, J.; Foulks, G.N.; Pepose, J.S.; Sullivan, B.D. Tear osmolarity in the diagnosis and management of dry eye disease. Am. J. Ophthalmol. 2011, 151, 792-798.e791. [CrossRef] [PubMed]

23. Mathers, W.D.; Lane, J.A.; Sutphin, J.E.; Zimmerman, M.B. Model for ocular tear film function. Cornea 1996, 15, 110-119. [CrossRef] [PubMed]

24. Rolando, M.; Refojo, M.F.; Kenyon, K.R. Increased tear evaporation in eyes with keratoconjunctivitis sicca. Arch. Ophthalmol. 1983, 101, 557-558. [CrossRef]

25. Tomlinson, A.; Khanal, S.; Ramaesh, K.; Diaper, C.; McFadyen, A. Tear film osmolarity: Determination of a referent for dry eye diagnosis. Investig. Ophthalmol. Vis. Sci. 2006, 47, 4309-4315. [CrossRef]

26. Versura, P.; Profazio, V.; Campos, E.C. Performance of tear osmolarity compared to previous diagnostic tests for dry eye diseases. Curr. Eye Res. 2010, 35, 553-564. [CrossRef] [PubMed]

27. Med Pharma. I-Pen Osmolarity System Usual Manual; I-Med Pharma Inc.: Dollard-des-Ormeaux, QC, Canada, 2016.

28. Park, J.Y.; Kim, B.G.; Kim, J.S.; Hwang, J.H. Matrix Metalloproteinase 9 Point-of-Care Immunoassay Result Predicts Response to Topical Cyclosporine Treatment in Dry Eye Disease. Transl. Vis. Sci. Technol. 2018, 7, 31. [CrossRef]

29. Ozcura, F.; Aydin, S.; Helvaci, M.R. Ocular surface disease index for the diagnosis of dry eye syndrome. Ocul. Immunol. Inflamm. 2007, 15, 389-393. [CrossRef] [PubMed]

30. The definition and classification of dry eye disease: Report of the Definition and Classification Subcommittee of the International Dry Eye WorkShop (2007). Ocul. Surf. 2007, 5, 75-92. [CrossRef]

31. Begley, C.G.; Chalmers, R.L.; Abetz, L.; Venkataraman, K.; Mertzanis, P.; Caffery, B.A.; Snyder, C.; Edrington, T.; Nelson, D.; Simpson, T. The Relationship between Habitual Patient-Reported Symptoms and Clinical Signs among Patients with Dry Eye of Varying Severity. Investig. Ophthalmol. Vis. Sci. 2003, 44, 4753-4761. [CrossRef]

32. Nichols, K.K.; Nichols, J.J.; Mitchell, G.L. The lack of association between signs and symptoms in patients with dry eye disease. Cornea 2004, 23, 762-770. [CrossRef] 
33. Gupta, P.K.; Drinkwater, O.J.; VanDusen, K.W.; Brissette, A.R.; Starr, C.E. Prevalence of ocular surface dysfunction in patients presenting for cataract surgery evaluation. J. Cataract Refract. Surg. 2018, 44, 1090-1096. [CrossRef]

34. Cho, Y.K.; Kim, M.S. Dry eye after cataract surgery and associated intraoperative risk factors. Korean J. Ophthalmol. 2009, $23,65-73$. [CrossRef] [PubMed]

35. Ishrat, S.; Nema, N.; Chandravanshi, S.C.L. Incidence and pattern of dry eye after cataract surgery. Saudi J. Ophthalmol. 2019, 33, 34-40. [CrossRef]

36. Moon, H.; Yoon, J.H.; Hyun, S.H.; Kim, K.H. Short-term influence of aspirating speculum use on dry eye after cataract surgery: A prospective study. Cornea 2014, 33, 373-375. [CrossRef] [PubMed]

37. Ram, J.; Gupta, A.; Brar, G.; Kaushik, S.; Gupta, A. Outcomes of phacoemulsification in patients with dry eye. J. Cataract Refract. Surg. 2002, 28, 1386-1389. [CrossRef]

38. Ram, J.; Sharma, A.; Pandav, S.S.; Gupta, A.; Bambery, P. Cataract surgery in patients with dry eyes. J. Cataract Refract. Surg. 1998, 24, 1119-1124. [CrossRef]

39. Chung, Y.W.; Oh, T.H.; Chung, S.K. The effect of topical cyclosporine $0.05 \%$ on dry eye after cataract surgery. Korean J. Ophthalmol. 2013, 27, 167-171. [CrossRef]

40. Oh, T.; Jung, Y.; Chang, D.; Kim, J.; Kim, H. Changes in the tear film and ocular surface after cataract surgery. Jpn. J. Ophthalmol. 2012, 56, 113-118. [CrossRef]

41. Ju, R.H.; Chen, Y.; Chen, H.S.; Zhou, W.J.; Yang, W.; Lin, Z.D.; Wu, Z.M. Changes in ocular surface status and dry eye symptoms following femtosecond laser-assisted cataract surgery. Int. J. Ophthalmol. 2019, 12, 1122-1126. [CrossRef]

42. Craig, J.P.; Nichols, K.K.; Akpek, E.K.; Caffery, B.; Dua, H.S.; Joo, C.K.; Liu, Z.; Nelson, J.D.; Nichols, J.J.; Tsubota, K.; et al. TFOS DEWS II Definition and Classification Report. Ocul. Surf. 2017, 15, 276-283. [CrossRef] [PubMed]

43. Iglesias, E.; Sajnani, R.; Levitt, R.C.; Sarantopoulos, C.D.; Galor, A. Epidemiology of Persistent Dry Eye-Like Symptoms After Cataract Surgery. Cornea 2018, 37, 893-898. [CrossRef]

44. Sajnani, R.; Raia, S.; Gibbons, A.; Chang, V.; Karp, C.L.; Sarantopoulos, C.D.; Levitt, R.C.; Galor, A. Epidemiology of Persistent Postsurgical Pain Manifesting as Dry Eye-Like Symptoms After Cataract Surgery. Cornea 2018, 37, 1535-1541. [CrossRef]

45. Aragona, P.; Aguennouz, M.; Rania, L.; Postorino, E.; Sommario, M.S.; Roszkowska, A.M.; De Pasquale, M.G.; Pisani, A.; Puzzolo, D. Matrix metalloproteinase 9 and transglutaminase 2 expression at the ocular surface in patients with different forms of dry eye disease. Ophthalmology 2015, 122, 62-71. [CrossRef] [PubMed]

46. De Paiva, C.S.; Corrales, R.M.; Villarreal, A.L.; Farley, W.J.; Li, D.Q.; Stern, M.E.; Pflugfelder, S.C. Corticosteroid and doxycycline suppress MMP-9 and inflammatory cytokine expression, MAPK activation in the corneal epithelium in experimental dry eye. Exp. Eye Res. 2006, 83, 526-535. [CrossRef]

47. Li, D.Q.; Luo, L.; Chen, Z.; Kim, H.S.; Song, X.J.; Pflugfelder, S.C. JNK and ERK MAP kinases mediate induction of IL-1beta, TNF-alpha and IL-8 following hyperosmolar stress in human limbal epithelial cells. Exp. Eye Res. 2006, 82, 588-596. [CrossRef]

48. Massingale, M.L.; Li, X.; Vallabhajosyula, M.; Chen, D.; Wei, Y.; Asbell, P.A. Analysis of Inflammatory Cytokines in the Tears of Dry Eye Patients. Cornea 2009, 28, 1023-1027. [CrossRef]

49. Lanza, N.L.; Valenzuela, F.; Perez, V.L.; Galor, A. The Matrix Metalloproteinase 9 Point-of-Care Test in Dry Eye. Ocul. Surf. 2016, 14, 189-195. [CrossRef]

50. Yu, Y.; Hua, H.; Wu, M.; Yu, Y.; Yu, W.; Lai, K.; Yao, K. Evaluation of dry eye after femtosecond laser-assisted cataract surgery. J. Cataract Refract. Surg. 2015, 41, 2614-2623. [CrossRef] [PubMed]

51. Konomi, K.; Chen, L.L.; Tarko, R.S.; Scally, A.; Schaumberg, D.A.; Azar, D.; Dartt, D.A. Preoperative characteristics and a potential mechanism of chronic dry eye after LASIK. Investig. Ophthalmol. Vis. Sci. 2008, 49, 168-174. [CrossRef]

52. Rodriguez, A.E.; Rodriguez-Prats, J.L.; Hamdi, I.M.; Galal, A.; Awadalla, M.; Alio, J.L. Comparison of goblet cell density after femtosecond laser and mechanical microkeratome in LASIK. Investig. Ophthalmol. Vis. Sci. 2007, 48, 2570-2575. [CrossRef]

53. Rodriguez-Prats, J.L.; Hamdi, I.M.; Rodriguez, A.E.; Galal, A.; Alio, J.L. Effect of suction ring application during LASIK on goblet cell density. J. Refract. Surg. 2007, 23, 559-562. [CrossRef] [PubMed]

54. Shin, S.Y.; Lee, Y.J. Conjunctival changes induced by LASIK suction ring in a rabbit model. Ophthalmic Res. 2006, 38, 343-349. [CrossRef]

55. Igarashi, T.; Takahashi, H.; Kobayashi, M.; Kunishige, T.; Arima, T.; Fujimoto, C.; Suzuki, H.; Okuda, T.; Takahashi, H. Changes in Tear Osmolarity after Cataract Surgery. J. Nippon. Med. Sch. 2021, 88, 204-208. [CrossRef]

56. Lee, J.H.; Min, K.; Kim, S.K.; Kim, E.K.; Kim, T.-I. Inflammatory Cytokine and Osmolarity Changes in the Tears of Dry Eye Patients Treated with Topical 1\% Methylprednisolone. Yonsei Med. J. 2014, 55, 203-208. [CrossRef] [PubMed]

57. Bron, A.J.; Tomlinson, A.; Foulks, G.N.; Pepose, J.S.; Baudouin, C.; Geerling, G.; Nichols, K.K.; Lemp, M.A. Rethinking dry eye disease: A perspective on clinical implications. Ocul. Surf. 2014, 12, S1-S31. [CrossRef]

58. Epitropoulos, A.T.; Matossian, C.; Berdy, G.J.; Malhotra, R.P.; Potvin, R. Effect of tear osmolarity on repeatability of keratometry for cataract surgery planning. J. Cataract Refract. Surg. 2015, 41, 1672-1677. [CrossRef]

59. Goto, E.; Yagi, Y.; Matsumoto, Y.; Tsubota, K. Impaired functional visual acuity of dry eye patients. Am. J. Ophthalmol. 2002, 133, 181-186. [CrossRef]

60. Tutt, R.; Bradley, A.; Begley, C.; Thibos, L.N. Optical and visual impact of tear break-up in human eyes. Investig. Ophthalmol. Vis. Sci. 2000, 41, 4117-4123. 